\title{
Activity strategy and pattern of the Siberian jerboa (Orientallactaga sibirica) in the Alxa desert region, China
}

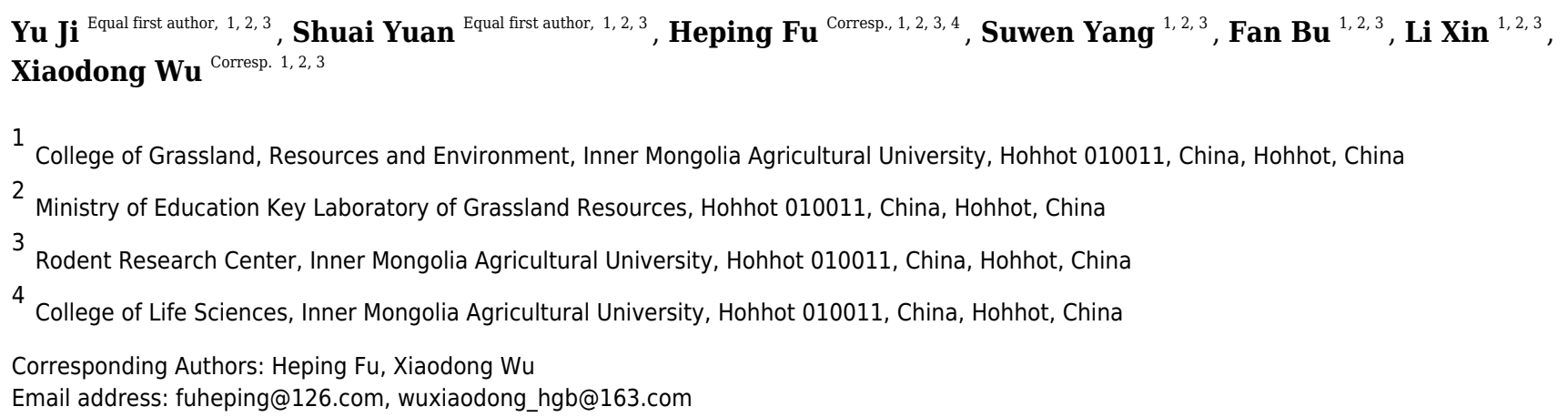

Rodents exhibit seasonal changes in their activity patterns as an essential survival strategy. We studied the activity patterns and strategies of the Siberian jerboa (Orientallactaga sibirica) in the Alxa desert region to better understand the habitats and behavioural ecology of xeric rodents. We conducted an experiment using three plots to monitor the duration, time, and frequency of the active period of the Siberian jerboa using infrared cameras in the Alxa field workstation, Inner Mongolia, China in 2017. The relationships between the activity time and frequency, biological factors ( perceived predation risk, food resources, and species composition), and abiotic factors (temperature, air moisture, wind speed) were analysed using Redundancy Analysis (RDA). Our results showed that: 1) relative humidity mainly affected activities in the springtime; temperature, relative humidity and interspecific competition mainly affected activities in the summertime; relative humidity and perceived predation risk mainly influenced activities in the autumn. 2) The activity pattern of the Siberian jerboa altered depending on the season. The activity of the Siberian jerboa was found to be bimodal in spring and summer, and was trimodal in autumn. The activity time and frequency in autumn were significantly lower than the spring. 3) Animals possess the ability to integrate disparate sources of information about danger to optimize energy gain. The jerboa adapted different responses to predation risks and competition in different seasons according to the demand for food resources. 
1 Activity strategy and pattern of the Siberian jerboa

2 (Orientallactaga sibirica) in the Alxa desert region, China

$3 \mathrm{Yu} \mathrm{Ji} \mathrm{H}^{\mathrm{Equal}}$ first author, 1,2,3, Shuai Yuan Equal first author, $1,2,3$, Heping $\mathrm{Fu}^{1,2,3,4,{ }^{*} \text {,Suwen Yang }}{ }^{1,2,3}$, Fan $\mathrm{Bu}^{1,2,3}$,

4 Xin $\mathrm{Li}^{1,2,3}$, Xiaodong $\mathrm{Wu}^{1,2,3, *}$

$5{ }^{1}$ College of Grassland, Resources and Environment, Inner Mongolia Agricultural University,

6 Hohhot 010011, China

$7 \quad 2$ Ministry of Education Key Laboratory of Grassland Resources, Hohhot 010011, China

$8 \quad{ }^{3}$ Rodent Research Center, Inner Mongolia Agricultural University, Hohhot 010011, China

$9{ }^{4}$ College of Life Science, Inner Mongolia Agricultural University, Hohhot 010011, China

10 Corresponding Author:

11 Heping Fu, fuheping@126.com

12 Xiaodong Wu, wuxiaodong hgb@163.com

13306 Zhaowuda road, Hohhot, Inner Mongolia, 010011, China

\begin{abstract}
Rodents exhibit seasonal changes in their activity patterns as an essential survival strategy. We studied the activity patterns and strategies of the Siberian jerboa (Orientallactaga sibirica) in the Alxa desert region to better understand the habitats and behavioural ecology of xeric rodents. We conducted an experiment using three plots to monitor the duration, time, and frequency of the active period of the Siberian jerboa using infrared cameras in the Alxa field workstation, Inner Mongolia, China in 2017. The relationships between the activity time and frequency, biological factors (perceived predation risk, food resources, and species composition), and abiotic factors (temperature, air moisture, wind speed) were analysed using Redundancy Analysis (RDA). Our results showed that: 1) relative humidity mainly affected activities in the springtime; temperature, relative humidity and interspecific competition mainly affected activities in the summertime; relative humidity and perceived predation risk mainly influenced activities in the autumn. 2) The activity pattern of the Siberian jerboa altered depending on the season. The activity of the Siberian jerboa was found to be bimodal in spring and summer, and was trimodal in autumn. The activity time and frequency in autumn were significantly lower than the spring. 3) Animals possess the ability to integrate disparate sources of information about danger to optimize energy gain. The jerboa adapted different responses to predation risks and competition in different seasons according to the demand for food resources.
\end{abstract}

\title{
Introduction
}

The activity patterns of animals indicate various evolutionary adaptations. Each population has a seasonal activity pattern that is best suited to local conditions. Individuals optimizing their activity patterns have the most significant advantage in natural selection (Kronfeld-Schor \& Dayan, 2008; Hemami et al., 2011; Mastureh et al., 2017; Mansureh \& Morteza, 2018). The activity pattern of 
animals is a comprehensive adaptation to the periodic changes of various environmental conditions, including non-biological conditions such as light, temperature, humidity, food need, intra-species community relations, and natural enemies (Halle, 2000). Activity patterns are also influenced by predation risk (Orr, 1992; Fenn \& Macdonald, 1995), competition (Alanara \& Metcalfe, 2001; Kronfeld-Schor \& Dayan, 2008), food availability (Orpwood et al., 2006), reproductive status (Schrader et al., 2009), nutritional status (Metcalfe and Steele, 2001), habitat (Wasserberg et al., 2006), and physical factors (Fraser et al., 1993). Temperature affects animal activity patterns, and the effects of temperature on behaviour and its interactions with other factors have been experimentally studied (Levy et al., 2007). Research has indicated that the activity period of animals may change with seasonal temperature variations (Lee et al., 2010). Activity periods may also vary between microhabitats with different wind speeds (Melcher et al., 1990). Air moisture is particularly important for animals living in warm or hot environments due to the influence of air moisture on heat balance (Kausrud et al., 2008; Shuai et al., 2014). The availability of food is the primary factor influencing changes in the activity patterns of rodents. Studies have shown that ecological factors directly related to energy demand affected activity patterns of animals (Denis, 1980). Predation risk may be another ecological factor affecting activity patterns (Claire \& Leiner, 2017). Although there are many findings related to factors that influence animal activity patterns, most studies have focused on only one aspect and have failed to consider the relative importance of other factors (Shuai et al., 2014; Kei \& Motokazu, 2017). The species composition, including the presence or absence of potential competitors (Elke et al. 2013), of the rodent community also influences the nocturnal activity patterns of rodents. We sought to determine the main factors affecting the activity of the Siberian jerboa.

Studies have found that rodent activity patterns in desert areas change with the seasons (Gregory et al., 2001; Richman \& Kent, 1973). For example, golden spiny mice (Acomys russatus) shown diurnal activity patterns with a midday peak in winter and a bimodal pattern with peaks in morning and afternoon in the summer (Shkolnik, 1971; Kronfeld-Schor \& Dayan, 2008). It has been speculated that the less typical diurnal pattern demonstrated by A. russatus is due to competitive displacement (Kronfeld et al., 1996). The kangaroo rat (Dipodomys merriami) responds to winter by decreasing its activity in November (Richman \& Kent, 1973). Seasonal shifts in activity patterns have also been observed in studies of other rodent species, and analysis of daily activity rhythms have shown that the number of peak periods of activity are higher during high-temperature seasons than that in low-temperature seasons. Research of monthly activity rhythms demonstrated that activity was higher in high-temperature months than in low-temperature months. For example, the activity pattern of Verreaux's sifaka (Propithecus verreauxi) was bimodal during the lowtemperature winter period to reduce energy loss, and unimodal with more extended activity periods in high-temperature summer (Erkert \& Kappeler, 2004). The Japanese flying squirrel (Pteromys momonga) is bimodal in temperate seasons and trimodal in cold seasons. This species reduces its active time in the cold season to reduce energy consumption caused by long-term exposure to low temperatures (Lee et al., 2010). Rodents alter their activity patterns when external environmental factors change with the season. Variations in the external biological and abiotic environment cause the transformation of animal activity patterns for reasons of survival, and animals usually adjust 
their activity frequencies and times to cope with these changes (Delany, 1972).

A pattern has emerged in some studies to show that abiotic environmental factors such as temperature often provide a range within which rodents are active. The quantity or quality of food will determine activity levels within this range (Bartholomew and Cade, 1957). Emlen (1966), MacArthur, and Pianka (1966) created the optimal foraging theory, which attempts to explain and predict many aspects of animal foraging behaviour. This theory supposes that the foraging behaviours and adaptability of animals are maximized through natural selection, but are subject to certain restrictions. The optimal foraging theory predicts that risk-taking decisions vary with the perceived threat level (Kelly et al., 2020) and that animals have to face trade-offs when they encounter predators when foraging. Biological factors such as food resources and predation risk may change the survival strategy that an animal will adopt. An animal's response to predatory pressure may be to remove itself from the predator's foraging microhabitat (predator avoidance mechanism), or to reduce the probability of successful predation within the predator's perceptual domain (anti-predator mechanism). Predator avoidance mechanisms are typical patterns of behaviour exhibited by animals; these mechanisms include occupying (e.g., cover or dense vegetation), changing their foraging habitats (spatial avoidance), or adjusting their activity periods (temporal avoidance). A variety of morphological and behaviour traits represent antipredator mechanisms (Brodie, 1991). The ability of animals to bear the risk of predation is related to their own characteristics. An animal with a higher basal metabolism is more sensitive to the risk of predation. When animals forage under conditions of food shortage, they will change strategy from risk-aversion to risk-proneness (Wei et al., 2004).

The Siberian jerboa (Orientallactaga sibirica) (Michaux \& Shenbrot, 2017) is a rodent species found predominantly in the desert and semi-desert of Alxa. It enters into hibernation in early September and emerges from hibernation in late March or early April of the following year (Li \& Han, 1990; Zhou et al., 1992). The Siberian jerboa is usually active in the evening and before dawn, and is not easily found in daylight hours (Liang \& Xiao, 1982; Dong et al., 2006). We sought to determine the activity pattern of the five-toed jerboa, its impact factors, whether its activity pattern changes with the seasons and the reason for the shift. We also investigated the survival strategies involved in the variations of activity.

We selected biological factors (perceived predation risk, food resources, and species composition of rodent community), and abiotic factors (temperature, air moisture, wind speed) as possible influencing elements for the jerboa activity patterns to explore whether the Siberian jerboa had the same seasonal variations as other rodent, and to determine the survival strategies and other factors behind these variations. We proposed the following hypotheses: (1) In spring, after a long hibernation period, energy supply is incredibly important and food resources may be an essential factor influencing the activity pattern of Siberian jerboa. In summer, high temperatures may limit the activity of the jerboa, but to compensate for this thermal constraint, wind speed, and air humidity are influential. Food resources become critical in autumn to store the energy needed during the long hibernation period. (2) There were seasonal changes in the activity patterns of the Siberian jerboa. The dominant factor driving this shift may be competition or temperature. (3) The mechanism driving this shift is risk-taking decisions should vary in response to perceived levels 
of threat.

\section{Materials and methods}

\section{Study area}

Our study was conducted in the southern part of Alxa Zuo Qi at the eastern edge of the Tengger Desert, Inner Mongolia, China (E104 $\left.{ }^{\circ} 10^{\prime}-105^{\circ} 30^{\prime}, \mathrm{N}^{\circ} 7^{\circ} 24^{\prime}-38^{\circ} 25^{\prime}\right)$ from April to October, 2017. The area has a continental climate with cold, dry winters and warm summers. Annual temperatures range from -36 to $42{ }^{\circ} \mathrm{C}$ with a mean of $8.3{ }^{\circ} \mathrm{C}$. Annual precipitation ranges from 45 to $215 \mathrm{~mm}$ with approximately 70 percent of precipitation falling from June to September. The potential evaporation range is from 3,000 to $4,700 \mathrm{~mm}$, and the annual frost-free period is 156 days. The Siberian jerboa is a common species distributed throughout the study site. Approximately $5-15 \%$ of the ground is covered with shrubs, forbs, and some gramineous plants. Shrubs mainly consisted of Zygophyllum xanthoxylon, Nitraria tangutorum, Caragana brachypoda, Ceratoides latens, Oxytropis aciphylla, Artemisia sphaerocephala, and Artemisia xerophytica with Reaumuria soongorica as the dominant species. The major grasses/forbs species were Cleistogenes squarosa, Peqanum nigellastrum, Cynanchum komarovii, Salsola pestifer, Suaeda glauca, Bassia dasyphylla, Corispermum mongolicum, Artemisia dubia, and Plantago lessingii (Yuan et al., 2018). Coexistent rodent species included Dipodidae (Orientallactaga sibirica, and Dipus sagitta), Cricetidae (Meriones meridianus, Cricetulus barabensis, and Phodopus roborovskii) and Sciuridae (Spermophilus alaschanicus). The natural enemies of rodents in the area are corsac (Vulpes corsac), eagle owls (Bubo bubo), and snake (Agkistrodon halys). According to our field observations, snakes, eagle owls, and foxes are active at night. The spring season is from March to May, summer is from June to August, autumn is from September to November, and winter is from December to February of the following year according to the climate characteristics of the test site.

\section{Camera trapping}

We deployed camera traps in three plots, each approximately $1 \mathrm{hm}^{2}$ in area, each separated by more than 500 meters. We deployed a survey infrared camera (Infrared monitor E1B, Lianyungang Jinsheng Technology Co., Ltd., China) to each plot. All cameras were active in May (spring), July (summer), and September (autumn) each year. Since the Siberian jerboa is a nocturnal rodent, the cameras were active from 19:00 to 07:00 the next day, divided into 12 time periods (i.e., 19:00-20:00, 20:00-21:00, and so on). Cameras functioned for four consecutive days each month for a total of 36 trap nights. Each camera was placed on a stake approximately $30 \mathrm{~cm}$ above the ground facing a lure 1.5-2.0 m away. Vegetation in the camera's line of sight was cleared to prevent false triggers. A peanut (Arachis hypogaea) was used as the lure. A pre-experiment check was conducted on the placement of the infrared cameras. Infrared cameras were randomly placed in the territory of the Siberian jerboa to find out where this rodent was active and we selected the active sites for our observations. The camera parameters were set to shooting mode (video), and video was recorded for 2 min when triggered, with no quiet period between trigger 
events. We checked the performance of the camera and replaced the battery and storage card every morning when data was collected. The videos were downloaded to a computer and each camera was assigned a point number. We identified each wildlife video and entered information on each video into an Excel table according to the camera number and appearance time to avoid repeatedly counting the activity information of the same animal in a short time. Multiple videos of the same animal within 30 minutes are entered as one record. We identified each photo of an animal for its species, recorded the time and date, and rated each photo as a dependent or independent event. An independent event was defined as the number of distinctly different individuals of a species detected within a 30-min period (Di Bitetti et al., 2006; Davis et al., 2011; Murphy et al., 2016). As we were unable to discriminate individual small mammals, each detection event was noted as one animal, unless there were multiple animals in the images. We defined an independent event as (1) consecutive photographs of different individuals of the same or different species, (2) consecutive photographs of individuals of the same species taken more than 0.5 hours apart, (3) non-consecutive photos of individuals of the same species (O'Brien et al., 2003; Duquette et al., 2017). We watched the video and recorded the duration of each appearance of jerboa and summed up the period of each appearance of an animal within a $60 \mathrm{~min}$ period, which was recorded as the activity time (O'Brien et al., 2003). Vigilance behaviour was defined as a series of physical action response behaviours exhibited by animals in response to existing or potential risks in the surrounding environment (Wang et al., 2015). It can be divided into the following cases: 1) Tweet: when danger is detected, a sitting, standing, or squatting posture is used to look directly at the threat and a series of screams are emitted to warn other members of the same species; 2) Alert: interruption of the ongoing behaviour (such as running, feeding, foraging, etc.), assume the squat posture, static, or accompanied by a rapid head twist to observe the surrounding environment to determine whether there is danger around, generally for no more than $3 \mathrm{~s} ; 3$ ) Watching: observe the movement of the surrounding environment by standing, sitting, or squatting, and the field accompanied by the head writhing for a longer time than $3 \mathrm{~s}$; 4) Avoiding: interruption of the ongoing behaviour (such as running, feeding, foraging, etc.) when danger is detected, or a call is heard, to quickly run back to the den, sometimes accompanied by a cry of alarm.

\section{Abiotic factors}

Climate data were collected from the Luanjingtan Weather station of Alax, and the average distance from the study area was $5.5 \mathrm{~km}$. The climate data reflected the local environmental conditions in the study plots (Wu et al., 2016). We collected hourly data for temperature, relative humidity, and wind speed from the China Meteorological Administration (http://www.cma.gov.cn/) over the same four days that the camera operated each month.

\section{Biological factors}

Food resource

We conducted vegetation sampling in the three plots in May, July, and September in 2017. We randomly placed three $100-\mathrm{m}^{2}$ square sampling plots on each treatment unit to sample shrubs and 
201 randomly placed three $1-\mathrm{m}^{2}$ quadrats in each $100-\mathrm{m}^{2}$ square plot to sample grasses and forbs. Three shrubs of each species were randomly selected from a shrub sample of $100-\mathrm{m}^{2}$, their crowns were measured and an appropriate amount of the aboveground part was taken. Samples were dried and the dry weight was taken. We measured the height of herb samples taken from a $1-\mathrm{m}^{2} \mathrm{plot}$, cut the herbs and dried them, then took the dry weight (Yuan et al., 2018). We estimated the aboveground standing biomass of shrubs, grasses, and forbs by species. Siberian jerboa are known to feed on the green parts of plants, the underground parts of plants, and seeds and insects in approximately equal proportion (Shenbrot et al., 2008). The same species distributed in different regions may also have different diets. We conducted feeding behaviour experiments of the Siberian jerboa were conducted in 2017 to determine the food resources in the study sites. The experiment was conducted as follows: Jerboas were live-trapped for each season (spring, summer, and autumn) from the desert habitat at a specified distance from the study sites and were fasted for $8 \mathrm{~h}$ before placing them into cages at dusk. A total of 14 jerboas were used (two males, and two females in May, three males and two females in July, three male and two female jerboas in September), weighing on average $95.80 \mathrm{~g} \pm 17.74 \mathrm{~g}$ (mean $\pm \mathrm{SD}$ ). Each jerboa was randomly assigned to one cage. We provided each plant species to each subject in $100 \mathrm{~mm}$ petri dishes placed in a randomized array with one species per dish. We fed jerboas every 3 hours, 2- 3 times per night. Ten to twelve plant species were fed in each feeding. The plant species fed to each jerboa was the same on the same night, but plant species were arranged randomly for each jerboa. We collected the remaining plants (including those cached throughout the cages) and plant remnants, and separated and weighed them by species when putting the new plant species in. The same plant species with same weight were placed outside of the cages as a control group to determine water loss. We calculated species composition of consumed plants by subtraction: $Y=A-\frac{B}{1-E}$, where $Y$ is mean food consumption, $A$ is mean initial weight, $B$ is mean remaining weight, $E$ is mean rate of water loss.

Preference index (PI) was calculated according to the daily food consumption of each plant by the formula: $P I=\frac{R I}{R B}$, where $P I$ is mean preference index, $R I$ is mean mass percentage of a plant's consumption in total food consumption, and $R B$ is mean mass percentage of a plant in total feed. The plant species was chosen by calculating the total food biomass and preference food biomass. Preferred foods were selected using the preference index (Batzli \& Pitelka, 1983). Preferred food biomass represented the food resources in the habitat.

\section{Perceived predation risk}

Vigilance time, vigilance frequency, and the distance of the vigilance alert are three indicators for assessing the perceived predation risk level of small rodents (Wan, 2019). Vigilance behaviour is one of the most essential countermeasures against predation, which depends heavily on the perceived predation risk (Limaa, 1987). Studies have shown that when the risk of predation increases, an animal's time-allocation strategy changes, reducing the risk of predation by increasing alertness, reducing foraging and other behaviors, and vice versa. It is believed that there is a trade-off between the alertness of animals and the activity intensity of other behaviors, such 
as foraging. This theory is called the predation risk allocation hypothesis (Wei et al., 2004; Steven $\&$ Peter, 1999) and it is believed that the higher the risk in the habitat, the greater the proportion of vigilance in total activity. To assess perceived predation risk, we measured the proportion of vigilance frequency in total activity frequency. We evaluated the perceived predation risk of Siberian jerboa by vigilance behavior, and verified our results using the vegetation structure and by excluding the influence of other factors on vigilance behavior.

Studies have shown that safety for small mammals is correlated with some measure of vegetation density, such as shrub coverage or grass height (Jacob \& Brown, 2000; Morris \& Davidson, 2000). Changes in vegetation may change an animal's perceived risk by increasing a potentially risky structure (Hagenah et al., 2009). Small-scale changes to the vegetation structure have been shown to alter the fear levels of prey, regardless of the abundance of predators (Wheeler \& Hik, 2014), and may influence the perceived predation risk more than actual predator cues. Reductions in ground cover, grass height, and horizontal structure may increase the perception of risks (Banasiak \& Shrader, 2015; Shrader et al., 2008). We used grass height and shrub coverage to assess predation risk. The calculation formulas are as follows:

$$
A H=\frac{(L H+M H+S H)}{3}
$$

$A H$ represents the average height $(\mathrm{cm})$ of a shrub species. $L H, M H$, and $S H$ represent the height $(\mathrm{cm})$ of large, medium, and small plants of the shrub species.

$$
C=\frac{3.14 \times S R^{2} \times \text { Den }}{100 \mathrm{~m}^{2}} \times 100 \%
$$

$C$ represents the average coverage per unit area of a shrub species (\%), and $S R$ represents $1 / 2$ (m) of the average canopy width of the shrub species.

$$
T C=\sum_{I=1}^{S} C_{i}
$$

$T C$ represents the total coverage per unit area of the shrub (\%), $S$ represents the number of species, and $C_{i}$ represents the coverage per unit area of the ith shrub (\%).

The vigilant behavior of animals is related to the risk of predation and the trade-off between vigilant and predation. Vigilance is affected by other factors, including an animal's sex and age (Randall et al., 2020; Xia et al., 2011), population size (Xia et al., 2011; Tchabovsky et al., 2001), individual position in the group, and environmental characteristics (Bekoff et al., 1995). Therefore, the vigilant behavior of animals is the result of the comprehensive effect under the influence of multiple factors (Bekoff et al., 1995). We excluded any coexisting nocturnal rodents when considering the vigilance behavior of our test species.

Spearman correlation analysis was used to analyze perceived predation risk, shrub coverage, and grass height (Table 1). Perceived predation risk was significantly negatively correlated with shrub coverage and grass height in spring and summer $(P<0.01)$. Perceived predation risk was significantly negatively correlated with grass height $(P<0.01)$, and negatively correlated with shrub coverage. Some studies of the desert jerboa have shown that certain species of the dipodidea prefer bare land with low vegetation coverage (Brown, 1980; Mansureh \& Morteza, 2018).We found that vigilance behavior may represent the perceived predation risk of Siberian jerboa to some 
extent, depending on the vegetation structure. Therefore, we measured the perceived predation risk of Siberian jerboa by the ratio of vigilance to all behaviors.

Spearman correlation analysis was used to analyze vigilance frequency and the relative population number for rodents in different seasons. The results showed no significant correlation between the vigilance frequency and the other three species of rodents co-existing in the same area. The influence of the population size of the Siberian jerboa on its vigilance behavior was also excluded (Table 2).

We found that it may be possible to evaluate the perceived predation risk of Siberian jerboa by its vigilance behavior.

\section{Species composition of the rodent community}

Rodents were live trapped for 4 consecutive days at 4-week intervals from April to October in 2017. Trapping did not occur from November to March. Traps were baited with fresh peanuts and checked in the morning and afternoon each day. The life span of the jerboa is longer than 2 years, and the average life span of non-jerboa species is shorter than 2 years. Each captured jerboa individual was sexed, and was marked with a $1.5 \mathrm{~g}$ aluminum leg ring $(0.4 \mathrm{~cm}$ diameter) with a unique identification number (ID) attached to the left hind foot. Each captured non-jerboa individual was sexed, marked with an electronic chip with a passive integrated transponder (Remex-X003, 2×1.8mm, Guangzhou Ruimai Intelligent Technology Co. Ltd., China) with a unique identification number (ID) injected under the pelage. The passive integrated transponder had a life span of 2 years. The capture station, sex, body weight, and reproductive condition of each individuals was recorded. Males were considered in reproductive condition if they had scrotal testes. Females were considered reproductive if they possessed enlarged nipples surrounded with white mammary tissue, or a bulging abdomen. In order to avoid accidental death, traps were closed on extremely warm or rainy days, and the trapping time was extended after extremely warm or rainy days to ensure 4 days of trapping in each month (Wu et al., 2016). To assess the effectiveness of the aluminum leg rings, we conducted a pre-experiment checks in 2018 and 2019. In April and May 2018, the leg rings and electronic chips were used to mark the jerboa simultaneously, and the loss of the leg rings and the electronic chip was recorded in September of the same year. At the beginning of this pre-experiment, we captured 21 Dipus sagitta individuals and 15 O. sibirica individuals in 2018. Six D. sagitta individuals and seven O. sibirica individuals were recaptured in September of 2019, with no loss of leg rings or chips.

We calculated the population relative number of rodents with a hundred cage capture rate (Wu et al. 2016). The calculation formula used is as follows:

$$
P=\frac{N}{H \times n} \times 100 \%
$$

$P$ is the capture rate; $N$ is the number of captured individuals; $H$ is total number of cages; $N$ is the number of consecutive days.

The nocturnal species of rodent coexisting with the Siberian jerboa were the D. sagitta, Phodopus roborovskii, and Meriones meridianus. The relative numbers of the three species were summed up as the number of coexisting species.

\section{Statistical analyses}


The activity time (the duration of the active period), activity frequency, predation risk, and food resources in different seasons were analysed by one-way ANOVA using SAS 9.0 software. All data were tested using the Shapiro-Wilk method and were found to be normally distributed (Table 3). Spearman correlation analysis was used to analysed the perceived predation risk, shrub coverage, and herb height. SPSS 21.0 was used for the analysis.

Multivariate analysis was performed with CANOCO 5.0 to explore the relationship between the environmental factors (biological and abiotic factors) and activity time and frequency over the different seasons using Redundancy Analysis (RDA). Detrended correspondence analysis (DCA) with detrending by segments was conducted to analyse the data on activity time and frequency in 2017 and to evaluate the gradient length of the first axis when deciding whether to use linear or unimodal based numerical methods. A Monte Carlo permutation test based on 499 random permutations was conducted to test the significance of the eigenvalues of the first canonical axis.

\section{Results \\ Food resources}

According to the preference index in different seasons, food resources varied among seasons. There were 12 species of plants favoured by Siberian jerboa in spring, 18 species favoured in summer, and 20 species favoured in autumn. There were differences in the feeding habits of the jerboa across the different seasons (Table 4 ) and significant differences in food resources available in different seasons. The preferred food biomass in autumn was significantly higher than that in spring and summer $\left(F_{2,24}=15.67, P<0.0001\right)$. The total food resources in spring were significantly less than that in summer and autumn $\left(F_{2,24}=18.16, P<0.0001\right)$. The total food resources were significantly higher than the preferred food biomass in different season (spring $F_{1,16}=5.04, P$ $=0.040$; summer $F_{1,16}=38.50, P<0.0001$; autumn $F_{1,16}=8.91, P=0.0093$ ) (Fig.1).

\section{Activity time and activity frequency}

The activity time of the jerboa was longer in spring and summer than in autumn $\left(F_{3,33}=5.64\right.$, $P=0.0078)$. There were two significant activity peaks in the daily activities, which appeared at 21:00-00:00 and 02:00-04:00, respectively, and were significantly different from other non-peaks times (spring $F_{11,132}=4.81, P<0.0001$; summer $F_{11,132}=2.86, P=0.0022$ ). The difference between the two activity peaks was not significant (spring $F_{4,55}=0.83, P=0.5100$; summer $F_{4,55}=0.87$, $P=0.4876$ ). There were three peaks of activity time in the autumn, which appeared at 20:00-21:00, 23:00-00:00 and 04:00-05:00, respectively, and were significantly different from non-peaks times $\left(F_{11,132}=2.23, P=0.0165\right)($ Fig.2A).

There was a significant difference between the activity frequency of the jerboa among three seasons $\left(F_{2,33}=10.67, P=0.0003\right)$. There were two peaks of activity frequency in spring and summer. The peaks appear in spring at 21:00-00:00 and 01:00-04:00, and were significantly different from non-peaks times $\left(F_{11,132}=3.71, P<0.0001\right)$. The peaks appeared in summer at 21:00-23:00 and 02:00-05:00, and were significantly different from non-peaks times $\left(F_{11,132}=3.84\right.$, $P<0.0001)$. There were three peaks of activity time in the autumn, which appeared at 20:00-21:00, 23:00-00:00, and 04:00-05:00, respectively, and were significantly different from non-peaks times $\left(F_{11,132}=3.87, P<0.0001\right)$. (Fig.2B). 
There was a significant difference between the total activity time each season. The total activity time in autumn was significantly shorter than in spring and summer. $\quad\left(F_{2,33}=5.64\right.$, $P=0.0078$ ) (Fig.2C). There was a significant difference between the total activity frequency in each season, following the order: spring $>$ summer $>$ autumn. $\left(F_{2,33}=1.67, P=0.0003\right)$ (Fig.2D).

\section{Perceived predation risk}

Vigilance behaviour in spring typically occurred between 05:00-06:00. In summer, vigilance behaviour typically occurred between 20:00-21:00. In autumn, vigilance behaviour occurred most often between 04:00-05:00 (Fig.3A, Fig.3B, Fig.3C). There were significant differences in the proportion of vigilance behaviour in the total activity periods in spring and autumn (Spring $F_{11,110}=5.70, P<0.0001$; Autumn $\left.F_{11,103}=2.93, P=0.0021\right)$, but no significant differences during summer $\left(F_{11,85}=1.64, P=0.1008\right)$.

There was a significant difference in daily vigilance behaviour frequency in different seasons $\left(F_{2,33}=4.05, P=0.0268\right)$. Perceived predation risk in spring was significantly higher than in autumn (Fig.3D).

\section{Species composition of the rodent community}

Among the rodents co-existing with the Siberian jerboa, the nocturnal species is the $D$. sagitta, $P$. roborovskii, and $M$. meridianus. There was no difference in the catch proportion of $D$. sagitta and M. meridianus between the seasons ( $D$. sagitta $F_{2,6}=1.11, P=0.3902 ;$ M. meridianus $\left.F_{2,6}=0.41, P=0.6812\right)$. There was a significant difference in the catch proportion of Siberian jerboa between the seasons $\left(F_{2,6}=4.85, P=0.0558\right)$. There was a significant difference in the total number of coexisting species between seasons $\left(F_{2,6}=7.25, P=0.0251\right)$ (Table 5).

\section{The relationship between environmental factors and activity pattern in different seasons}

The relationship between environmental factors and activity pattern in spring

The RDA results are displayed by an ordination diagram in which the dependent variable variables are depicted by blue arrows and impact factor by red arrows. The RDA biplot can be interpreted as follows: each blue arrow representing an impact factor determines a direction or axis in the diagram; red arrow representing activity time and frequency determine directions in the diagram. The correlations between activity time and frequency and impact factors are displayed by the angles of blue and red arrows. Arrows pointing in almost the same direction indicated a highly positive correlation, arrows oriented at right angles indicate nearly zero correlation, and arrows pointing in opposite directions indicate a highly negative correlation (Li \& Kendrick, 1995). Activity time and frequency and impact factors with the longest arrows are the most important in the analysis; the longer the arrows, the more confident one can be about the inferred correlation (Braak \& Prentice, 1988). Analysis of the relationships between different factors and activity time showed that the cosine value of the line segment representing activity time and temperature, food resource was positive. The cosine value of the line segment representing activity time and predation risk was 0 , so there was no correlation between activity time, and perceived predation risk. The cosine value of the line segment representing activity time, wind speed, relative humidity, and intraspecific competition were negative. Thus, there were negative correlations between activity time, wind speed, relative humidity, and intraspecific competition. The line segment representing temperature and relative humidity was longer, so temperature and relative humidity 
had a more significant impact on activity time.

The analysis of the relationships between environmental factors and activity frequency showed that the cosine value of the line segment representing active frequency and temperature and intraspecific competition was 0 , so there was no correlation. A positive correlation was found between activity frequency and predation risk, food resources and interspecific competition, and a negative correlation between activity frequency and relative humidity and wind speed. Among these factors, relative humidity had more significant impact on activity frequency, and this factor explained a larger proportion of variation in activity frequency.

Relative humidity was found to significantly affect the activity of Siberian jerboa in spring (RH $F=12.2, P=0.002$ ) (Fig. 4).

\section{The relationship between environment factors and activity pattern in summer}

There were negative correlations between activity time and relative humidity, temperature, wind speed, food resources, interspecific competition, intraspecific competition, and perceived predation risk. Among these factors, the lines representing relative humidity and temperature were longer, indicating that their influence on the activity time was relatively more important.

There were negative correlations between activity frequency and each factor. Among them, temperature and relative humidity had a more significant explanatory value, and had greater impacts on activity frequency.

Temperature and relative humidity had significant impacts on the activity of this rodent species in the summer ( $F=11.4, P=0.002$; RH $F=29.4, P=0.002$; InterC $F=4.4, P=0.028$ ) (Fig.5).

\section{The relationship between environment factors and activity pattern in autumn}

There were positive correlations between activity time and temperature and predation risk, food resources, and intraspecific competition. There were negative correlations between activity time and wind speed, and interspecific competition. There was no correlation between activity time and relative humidity. Among these factors, temperature, relative humidity, wind speed, and perceived predation risk had more considerable explanatory value, and their impact on activity frequency was more significant.

There were positive correlations between activity frequency and temperature and perceived predation risk. There was a negative correlation between activity frequency and relative humidity and wind speed and food resource.

Relative humidity, and perceived predation risk had significant impacts on the activity of this rodent species in the autumn (RH $F=6.5, P=0.010$; PR $F=33.5, P=0.002$ ) (Fig.6).

\section{Discussion}

There are costs and benefits associated with environmental and biotic demands, such that individuals usually tune their activities to the most favourable period in a day (Refinetti, 2008), and through this way individuals try to maximize their fitness when determining the proper time for basic survival and breeding activities. The Siberian jerboa had two peak periods in spring and summer, which were 21:00 -00:00 and 02:00 to 04:00. The activity time and frequency in autumn were very low, and there were three activity peaks. Our results are similar to those of a previous 
441 study of the ecological habits of Siberian jerboa (Liang et al., 1982). However, their research

442 showed that the Siberian jerboa had a high intensity period of activity in September. This difference may be due to different conditions between the experimental sites (Dong et al., 2006), suggesting that the species is adaptable to different environments. The optimal response of an organism to change in its environment is to minimize the cost to it through some kind of adaptive response (Wootton, 1990). Activity peaks of Siberian jerboa were bimodal during the spring and summer, and trimodal during the autumn. Studies have shown that rodents change the number of peaks of activity depending on the temperature of the seasons (Erkert \& Kappeler, 2004; Levy et al., 2007). The temperature of the region was lower in autumn than in summer, and reducing activities in the cooler autumn may minimize exposure in cold environments to reduce energy consumption (Cotton \& Parker, 2000). However, the temperature in autumn was similar to that in spring, or was even slightly higher than in spring. The difference in activity peaks may be attributed to the various factors that affected the activities in different seasons.

Our results showed that the factors affecting activities were different between seasons. In spring, relative humidity affected activities; in summer, temperature, relative humidity, and interspecific competition affected activities; in autumn, wind speed, relative humidity, and perceived predation risk affected activities. Although the relationship between temperature and activity time was negative in summer, the fundamental mechanism was the same as in the other two seasons and each species had its optimal temperature range (Rezende et al., 2003). Temperatures were higher in summer than in spring and autumn, exceeding the jerboa's temperature range. The relative humidity of different seasons had a negative impact on jerboa activities, which indicated that relative humidity was an important factor affecting the activity of this species. Other studies have shown that relative humidity promotes rodent activity in arid and semi-arid areas (Brodie et al., 1991), which was contrary to our findings. Studies have shown that the effects of humidity on animals vary, which may be due to the different ecological habits of each species (Zhang et al., 2006). The Siberian jerboa is a hibernating species (Zhou et al., 1992) and the activity of hibernating species is negatively related to humidity (Zhang et al., 2006). This difference in different seasons indicates that this species' activity in different seasons was not affected by a single factor, rather it was affected by a combination of multiple factors and the variations of the elements in different seasons. These results support our hypothesis. Therefore, seasonal differences in the number of activity peaks can be attributed to the activity being affected by various factors throughout different seasons. Some studies have suggested that the number of peak periods is affected by temperature (Kei \& Motokazu, 2017), but this is inconsistent with our results. We considered the influence of multiple factors while previous studies only considered the impact of single element (Ricardo et al., 2011). There are many findings related to factors that influence animal activity patterns. Most studies of activity patterns have tended to focus on only one aspect and have failed to consider the relative importance of other factors (Shuai et al., 2014; Kei \& Motokazu, 2017). Ecological and behavioural relationships between small mammals, especially rodents, are well-documented. It is reasonable to suspect that these factors may significantly affect the overall utilization of the local environment (Delany, 1972). Changes in animal activity patterns are adaptations to the general atmosphere. Therefore, it is reasonable to 
believe that changes in activity patterns may be influenced by multiple factors, not just one (Rant, 1978). Numerous factors must be taken into considered when analysing variation or change in animal activity patterns.

Research shows that temperature and relative humidity in different seasons play essential roles in influencing the activities of this rodent. In addition to factors that work together in different seasons under the influence of external abiotic factors, this rodent also responds to changes in biological factors. The risk of predation influences both activity pattern and habitat use (Werner et al., 1983, Berger, 1991). Food resources, perceived predation risk, and competition (interspecific and intraspecific competition) influenced activity levels in different seasons. The optimal foraging theory predicts that risk-taking decisions vary in response to perceived levels of threat (Emlen, 1966; Pianka, 1966; Kelly et al., 2020) and this was reflected in our results. Previous studies of other nocturnal mammals have shown that these animals reduce the risk of predation by restricting foraging activities or the duration of periodic activities (Gilbert \& Boutin, 1991; Mastureh et al., 2017; Mansureh \& Morteza, 2018).Siberian jerboa came out of hibernation in spring after a long hibernation period and required food to replenish their energy. The search for food resources is an important factor for triggering activities during this period. The increased need for food resources led to an increase in the time and frequency of activities to achieve the maximum use of food resources. The jerboa ignored the effect of perceived predation risk and intraspecific competition when seeking food resources and became risk-prone. Their foraging strategy during this season involved antipredator mechanisms and risk-proneness. In summer, when predation risk increases, the activity time and frequency of the jerboa decreased. The Siberian jerboa chose to avoid predation risk and competition. In summer, the adopted foraging strategy of the Siberian jerboa was risk-aversion and predator avoidance mechanisms, and reducing activity in the microhabitat with high feeding pressure increased survival value (Clarks, 1983). In autumn, the jerboa prepared to enter hibernation, and needed to store energy for the hibernation period. At this time, food resources guided the activities of this species. The decrease in food resource led to a reduction of activity time and frequency. The need for food made them ignore predation risks and interspecific competition. The campaign foraging strategy of the season was the same as in spring, driven by the demand for food resources. The selection of food resources by the Siberian jerboa was diverse depending on the season, which indicates that it used the micro-habitat differently and selected habitat as an antipredator strategy. The demand for food in autumn encouraged the rodent to expand the species of plants that were selectively eaten, thereby allowing it to obtain more food resources at a level where the overall vegetation biomass of the habitat was not high. There was no significant difference in the amount of food resources between spring and summer but the species was found to take greater risks in autumn when the food resources were abundant. Fooddeficient conditions generally cause animals to alter their behaviour from risk-aversion to riskproneness, leading scholars to propose the risk-sensitive foraging theory (McNamara \& Houston, 1990). Challenges in obtaining food resources lead Ochotona curzoniae to increase ground activity time to make full use of and protect their food resources (Zhang et al., 2005). Rodents reduced their exposure time and increased their activity frequency to reduce predation risk, which was one of the main countermeasures for adapting to high-risk environments (Yang et al., 2007). Animal 
have been shown to take risks to acquire resources when it is necessary for survival, even if the predation risk level increases (Barnard \& Hurst, 1987; Helfman, 1984). This behaviour may explain why spring and autumn seasons promoted different behavioural strategies than summer; spring and autumn required greater demands for food resource acquisition. The adoption of this foraging strategy is driven by the demand for food resources, not by the amount of food resources. Thus, the need for food was an important influencing factor of overall activity during different seasons and animals possess the ability to integrate disparate sources of information about danger to optimize energy gain (Chelsea et al., 2019).

\section{Conclusions}

We determined that factors affecting activities were different among various seasons. In spring, relative humidity mainly affected activities. In summer, temperature, relative humidity, and interspecific competition mainly affected activities. In autumn, relative humidity and perceived predation risk mainly affected activities. The activity pattern of the Siberian jerboa was altered in different seasons. The Siberian jerboa had two similar peak periods in spring and summer, and there were three activity peaks in autumn with lower activity time and frequency. Various factors are known to affect animal activity at different levels. Abiotic factors (temperature, relative humidity and wind speed) acted on the daily activity level and affected the number of peak periods of activity in different seasons. The demand for food resources affected the level of activity throughout the seasons. The jerboa adapted different responses to predation risks and competition in different seasons according to the amount of food resources available.

\section{Acknowledgements}

We would like to thank L.N. Ye, Y.N. Li, Q.W. Guo, D.S. Wen, Y.L. Jin, and L.L. Li for their assistance in data collection.

\section{References}

Alanara A, Burns MD, Metcalfe NB.2001. Intraspecific resource partitioning in brown trout: the temporal distribution of foraging is determined by social rank. Journal of Animal Ecology 70, 980-986.

Banasiak N, Shrader AM. 2015. Similarities in perceived predation risk prevent temporal partitioning of food by rodents in an African grassland. J Mammal 97: 483-489.

Barnard CJ, Hurst JL. 1987. Time constraints and prey selection in Common Shrew Sorex araneus L. Anim Behav 35:1827-1837.

Batzli GO, Pitelka FA. 1983. Nutritional Ecology of Microtine Rodents: Food Habits of Lemmings near Barrow, Alaska. Journal of Mammalogy 64:648-655.

Bekoff M. 1995. Cognitive ethology, vigilance, information gathering, and representation: Who might know what and why? Behav Processes 35:225-237.

Brodie ED, Formanowicz DR, Brodie ED. 1991. Predator avoidance and antipredator mechanisms:distinct pathways to survival. Ethology Ecology\&Evolution 3:73-77.

Brown RE. 1980. Rodents of the Kavir National Park, Iran. Mammalia 44: 89-96. 
Chelsea AO, Erika LP, Kate LN, Jennifer ES. 2019. Conspecific presence and microhabitat features influence foraging decisions across ontogeny in a facultatively social mammal. Behavioral Ecology and Sociobiology,2019,73: 114.

Claire P, Röpke Ferrando, Natália Oliveira Leiner (2017). Above-ground activity patterns of the semifossorial spiny rat Clyomys laticeps. Ethology Ecology \& Evolution.

Clarks JA.1983. Moonlight' s influence on predator prey interactions between short-eared owls (Asio flammeus) and deermice (Peromyscus maniculatus). Behav Ecol Sociobiol 13: 205-209.

Cotton CL, Parker KL.2000. Winter activity patterns of northern flying squirrels in sub-boreal forests. Can. J. Zool 78:1898-1901.

Daan S (1981). Adaptive daily strategies in behavior. In: Aschoff J ed. Biological rhythms. Plenum Press, New York, Pp. 275-298.

Davis ML, Kelly MJ, Stauffer DF. 2011. Carnivore co-existence and habitat use in the Mountain Pine Ridge Forest Reserve, Belize. Animal Conservation 14:56-65.

Delany MJ. 1972. The ecology of small rodents in tropical Africa. Mammal Rev 2:1-42.

Denis JB, Susan EW, Donald AD. 1980. Diurnal patterning of eight activities in 14 species of muroid rodents. Animal Learning and Behavior 8:322-330.

Di Bitetti MS, Paviolo A, C De Angelo. 2006. Density, habitat use and activity patterns of ocelots (Leopardus pardalis) in the Atlantic Forest of Misiones, Argentina. Journal of Zoology 270:153-163.

Dong WH, Hou XX, Yang YP. 2006. A Study on the Population Dynamics of A llactage sibirica Jerboa in the Central and Western Region of Inner Mongolia. Chin J Vector Bio \& Control 6:444-446.

Duquette JF, Ureña LB, Ortega JC, Cisneros IC, Moreno RC, Flores EE. 2017. Coiban Agouti (Dasyprocta coibae) Density and Temporal Activity on Coiba Island, Veraguas, Panama. Mammal Study 42:153-160.

Elke S, Franziska W, David B, Elisabeth H, Yuan S, Zhang FS, XD, Zhang, Fu HP, Wu XD. 2013. Species composition and interspecific behavior affects activity pattern of free-living desert hamsters in the Alashan Desert. Journal of Mammalogy 94: 448-458.

Emlen JM.1996. The Role of Time and Energy in Food Preference. The American Naturalist 100: 611.

Erkert HG, Kappeler PM. 2004. Arrived in the light: diel and seasonal activity patterns in wild Verreaux's sifakas (Propithecus v. verreauxi; Primates: Indriidae). Behav. Ecol. Sociobiol. 57:174-186.

Fenn MGP, Macdonald DW.1995. Use of middens by red foxes: risk reverses rhythms of rats. Journal of Mammalogy 76:130-136.

Fraser NHC, Metcalfe NB, Thorpe JE.1993. Temperature-dependent switch between diurnal and nocturnal foraging in salmon. Proceedings of the Royal Society, B. Biological Sciences 252:135-139.

Gilbert BS, Boutin S. 1991. Effect of moonlight on winter activity of snowshoe hares. Arctic Alpine Research 23: 6165.

Gregory E.D, Hanan A. El-Bakry, Eric MM, Wafaa MZ, Timothy JB. 2001. Wheel-Running Activity Patterns of Five Species of Desert Rodents. Biological Rhythm Research 32:1-16.

Hagenah N, Prins HHT, Olff H. 2009. Effects of Large Herbivores on Murid Rodents in a South African Savanna. $J$ Trop Ecol 25: 483-492.

Halle S. 2000. Ecological relevance of daily activity patterns. In: Halle S, Stenseth NC, ed. Activity patterns in small mammals. Berlin: Springer-Verlag, pp. 67-90.

Helfman G. 1984. Behavioural responses of prey fishes during predator-prey interactions. In: Feder M E, Lauder G 
V, eds. Predator-Prey Relationships: Perspectives and Approaches from the Study of Lower Vertebrates. Chicago: University of Chicago Press, 135-156.

Hemami M, Naderi G, Karami M, Mohammadi S. 2011. Nocturnal activity of Iranian jerboa, Allactaga firouzi (Mammalia: Rodentia: Dipodidae). Mammalia 75: 31-34.

Jacob J, Brown JS. 2000. Microhabitat use, giving-up densities and temporal activity as short-and long-term antipredator behaviors in common voles. Oikos 91: 131-138.

Kausrud KL, Mysterud A, Steen H, Vik JO, Østbye E, Cazelles B, Framstad E, Eikeset AM, Mysterud I, Solhøy T, Stenseth NC. (2008). Linking climate change to lemming cycles. Nature 456, 93-97.

Kei KS, Motokazu A (2017). Seasonal changes in activity patterns of Japanese flying squirrel Pteromys momonga. Behavioural Processes 143,13-16.

Kelly EC, Cypher BL, Germano DJ. 2020. Exploitative competition between desert kit foxes and coyotes in the Mojave Desert. Pacific Conservation Biology 26: 57-66.

Kent M. Van De Graff, Balda RP. 1973. Importance of green vegetation for reproduction in the kangaroo rat, Dipodomnys merriami merriami. J. Mammal 54:509-512.

Kronfeld N, Shargal E, Dayan T.1996. Population biology of coexisting Acomys species. In: Steinberger Y, ed., Preservation of Our World in the Wake of Change, Vol 4B. Israel Society for Ecology and Environmental Quality Sciences, Jerusalem, pp. 478-480.

Kronfeld-Schor N, Dayan T.2008. Activity patterns of rodents: the physiological ecology of biological rhythms. Biol Rhythm Res. 39:193-211.

Lee JE, Larsen RT, Flinders JT, Eggett DL.2010. Daily and seasonal patterns of activity at pygmy rabbit burrows in Utah. West N Am Nat. 70:189-197.

Levy O, Dayan T, Kronfeld-Schor N.2007. The relationship between the golden spiny mouse circadian system and its diurnal activity: an experimental field enclosures and laboratory study. Chronobiol Int. 24:599-613.

Li DW, Kendrick B. 1995. A year-round study on functional relationships of airborne fungi with meteorological factors. International journal of biometeorology 39: 74-80.

Li ZL, Han JF.1990. A preliminary study on the natural reproduction of several jerboa species. Chinese Journal of Zoology 5:27-28.

Liang JR, Xiao YF. 1982. Some Ecological Information of five-toed jerboa (Allactaga sibirica). Chinese Journal of Zoology 4:24-25.

Limaa S L. 1987.Vigilance while feeding and its relation to the risk of predation. Journal of Theoretical Biology 124: 303-316.

MacArthur RH, Pianka ER. 1966. On Optimal Use of a Patchy Environment. The American Naturalist 100: 603.

Mansureh K, Morteza N. 2018. Notes on habitat affinities of the Hotson's Jerboa Allactaga hotsoni Thomas, 1920 (Rodentia: Dipodidae) from Isfahan province, Iran. Journal of Wildlife and Biodiversity 2: 41-43

Mastureh D, Zohreh Z, Abdolreza K, Ali K. 2017. Nocturnal activity and habitat selection of Hotson Jerboa, Allactaga hotsoni Thomas, 1920 (Rodentia: Dipodidae). Journal of Wildlife and Biodiversity 1: 33-36.

McNamara JM, Houston AI. 1990. The value of fat reserves and the trade-off between starvation and predation. Acta Biotheoret 38:37-61.

Melcher JC, Armitage KB, Porter WP. 1990. Thermal influences on the activity and energetics of yellow-bellied marmots (Marmota flaviventris). Physiol Zool 63:803-820.

Metcalfe NB, Steele GI. 2001. Changing nutritional status causes a shift in the balance of nocturnal to diurnal activity 
in European minnows. Functional Ecology 15:304-309.

Morris DW, Davidson DL. 2000. Optimally foraging mice match patch use with habitat differences in fitness. Ecology 81: 2061-2066.

Murphy AJ, Goodman SM, Farris ZJ, Karpanty SM, Andrianjakarivelo V, Kelly MJ. 2016. Landscape trends in small mammal occupancy in the Makira- Masoala protected areas, northeastern Madagascar. Journal of Mammalog 98: $272-282$.

Nevo E.1999. Mosaic evolution of subterranean mammals: regression, progression, and global convergence. Oxford University Press, Oxford.Michaux \& Shenbrot. 2017 - Family Dipodidae (Jerboas). In: D.E. Wilson, T.E. Lacher, Jr. and R.A. Mittermeier (eds). Handbook of the Mammals of the World. Vol 7. Rodents II. Lynx Editions, Barcelona. Pp. 62-100.

O’Brien TG, Kinnaird M F, Wibisono HT.2003. Crouching tigers, hidden prey: sumatran tiger and prey populations in a tropical forest landscape. Animal Conservation 6, 131-139.

Orpwood JE, Griffiths SW, Armstrong JD.2006. Effects of food availability on temporal activity patterns and growth of Atlantic salmon. Journal of Animal Ecology 75, 677-685.

Orr MR.1992. Parasitic flies (Diptera: Phoridae) influence foraging rhythms and caste division of labor in the leafcutter ant, Atta cephalotes (Hymenoptera: Formicidae). Behavioral Ecology and Sociobiology 30, 395-402.

Randall JA, Konstantin AR, Debra MS. 2000. Antipredator behavior of a social desert rodent: footdrumming and alarm calling in the great gerbil, Rhombomys opiums. Behavioral Ecology and Sociobiology 48:110-118.

Rant PR.1978. Competition for resources. In: Snyder DP, ed. Populations of small mammals under natural conditions. Univ. Pittsburgh. Pymatuning Lab. Ecol. Spec. Pubis, Pennsylvania, pp: 38-51.

Refinetti R.2008. The diversity of temporal niches in mammals. Biol Rhythm Res 39, 173-192.

Rezende E., Cortés A, Bacigalupe LD, Nespolo RF, Bozinovic F.2003. Ambient temperature limits above ground activity of the subterranean rodent Spalacopus cyanus. Journal of Arid Environments 55, 63-74.

Ricardo P, António M, Pedro B.2011. Circadian activity rhythms in relation to season, sex and interspecific interactions in two Mediterranean voles. Animal Behaviour 81.

Richman OJ, Kent M. Van De Graff. 1973. Seasonal Activity and Reproductive Patterns of Five Species of Sonoran Desert Rodents. The American Midland Naturalist 90:118-126.

Schrader JA, Walaszczyk EJ, Smale L. 2009. Changing patterns of daily rhythmicity across reproductive states in diurnal female Nile grass rats (Arvicanthis niloticus). Physiology and Behavior 98:547-556.

Schrader JA, Walaszczyk EJ, Smale L.2009. Changing patterns of daily rhythmicity across reproductive states in diurnal female Nile grass rats (Arvicanthis niloticus). Physiology and Behavior 98, 547-556.

Shenbrot GI, Sokolov VE, Heptner VG, Koval'skaya Yu.M. 2008. Jerboas. Mammals of Russia and adjacent regions. Science Publishers Inc, Enfield, USA.

Shkolnik A.1971. Diurnal acitivity in a small desert rodent. Int J Biometeorology 15:115-120.

Shuai LY, Ren CL, Cao CS, Yan L, Zeng ZG.2014. Shifts in activity patterns of Microtus gregalis: a role of competition or temperature? Journal of Mammalogy 95, 960-967.

Steven LL, Peter AB.1999. Temporal variation in danger drives antipredator behavior: The predation risk allocation hypothesis. The American naturalist 153, 649-659.

Tchabovsky AV, Sergei VP. 2001. Intra-and interspecific variation in vigilance and foraging of two gerbillid rodents, Rhombomys opimus and Psammomys obesus: The effect of social environment. Animal Behaviour 62: 965-972. Braak CJF, Prentice IC.1988. A theory of gradient analysis. Adv Ecol Res 18:271-317. 
Wan WR. 2019. The relationship between population density,vegetation community structure and predation risk of Palteau Pika. Acta Agrestia Sinica 27: 350-355.

Wang TT, Hai SZ,Wang D.2015. Construction for the Ethogram of Brandt's Voles (Lasiopodpmys brandtii). Acta Agrestia sinica 23, 646-652.

Wasserberg G, Kotler BP, Abramsky Z.2006. The role of site, habitat, seasonality and competition in determining the nightly activity patterns of psammophilic gerbils in a centrifugally organized community. Oikos 112, 573-579.

Wei WH, Cao YF, Zang YM, Yin BF, Wang JL. 2004. Influence of the predation risk on the behavior of the plateau pika. Acta Zoologica Sinica 50(3): 319-325.

Wei WH, Yang SM, Fan RC, Zhou L.2004. The Response of Animal' s Foraging Behaviour to Predation Risk. Chinese Journal of Zoology 3, 84-90.

Wheeler HC, Hik DS. 2014. Giving-up densities and foraging behaviour indicate possible effects of shrub encroachment on arctic ground squirrels. Anim Behav 95: 1-8.

Wu XD, Yuan S, Fu HP, Zhang XD, Zhang FS, Gao QR. 2016. Responses of dominant rodentspecies to climate change in different disturbed habitats in the Alashan desert. Acta Ecologica Sinica 36:1765-1773.

Xia CJ, Xu WX, Yang WK, David B, Qiao JF, Liu W. 2011. Vigilance in Goitred gazelle (Gazella subgutturosa) : effect of seasons, sexes and group size. Acta Theriologica Sinica 31: 148-154.

Yang SM, Wei WH, Yin BF, Fan RC, Zhou WY.2007. The predation rosks of the plateau pika and plateau zokor and their survival strategies in the Alpine Meadow Ecosystem. Acta Ecologica Sinica 12, 4972-4978.

Yuan S, Fu HP, Wu XD, Yang SW, Malqin X, Yue XX.2018. Effects of grazing on the northern three-toed jerboa pre- and post-hibernation. Journal of Wildlife Management 82, 1588-1597.

Zhang XR, Luo YS, Du GY, Zhang ZX, Zhan W, Tian H.2006. Relation between humidity and animal. Acta Ecologiae Animalis Domastici 27, 1-5.

Zhang YM, Zhang ZB, Wei WH, Cao YF.2005. Time Allocation of Territorial Activity and Adaptations to Environment of Predation Risk by Plateau Pikas. Acta Theriologica Sinica 4, 23-28.

Zhou YL, Yang YP, Hou CX, Dong WH. 1992. The investigation on hibernation \& emergence from hibernation. Chinese Journal of Vector Biology and Control 1:32-36. 


\section{Table $\mathbf{1}$ (on next page)}

Correlation analysis of perceived predation risk and vegetation structure in different seasons

$*$ and $* *$ indicate significant correlation at 0.05 and 0.01 levels 


\begin{tabular}{|c|c|c|c|c|}
\hline \multirow[t]{2}{*}{ Season } & Item & Perceived predation risk & Grass height & Shrub coverage \\
\hline & Perceived predation risk & 1.000 & & \\
\hline \multirow[t]{3}{*}{ Spring } & Grass height & $-0.118^{* *}$ & 1.000 & \\
\hline & Shrub coverage & $-0.059 * *$ & $-0.224 * *$ & 1.000 \\
\hline & Perceived predation risk & 1.000 & & \\
\hline \multirow[t]{3}{*}{ Summer } & Grass height & $-0.282 * *$ & 1.000 & \\
\hline & Shrub coverage & $-0163 * *$ & -0.018 & 1.000 \\
\hline & Perceived predation risk & 1.000 & & \\
\hline \multirow[t]{2}{*}{ Autumn } & Grass height & $-0.342 * *$ & 1.000 & \\
\hline & Shrub coverage & -0.030 & 0.055 & 1.000 \\
\hline
\end{tabular}

2 Note: $*$ and $* *$ indicate significant correlation at 0.05 and 0.01 levels.

3 


\section{Table 2 (on next page)}

Correlation analysis of Vigilance frequency and the population relative number of rodents in different seasons

$*$ and $* *$ indicate significant correlation at 0.05 and 0.01 levels 
1

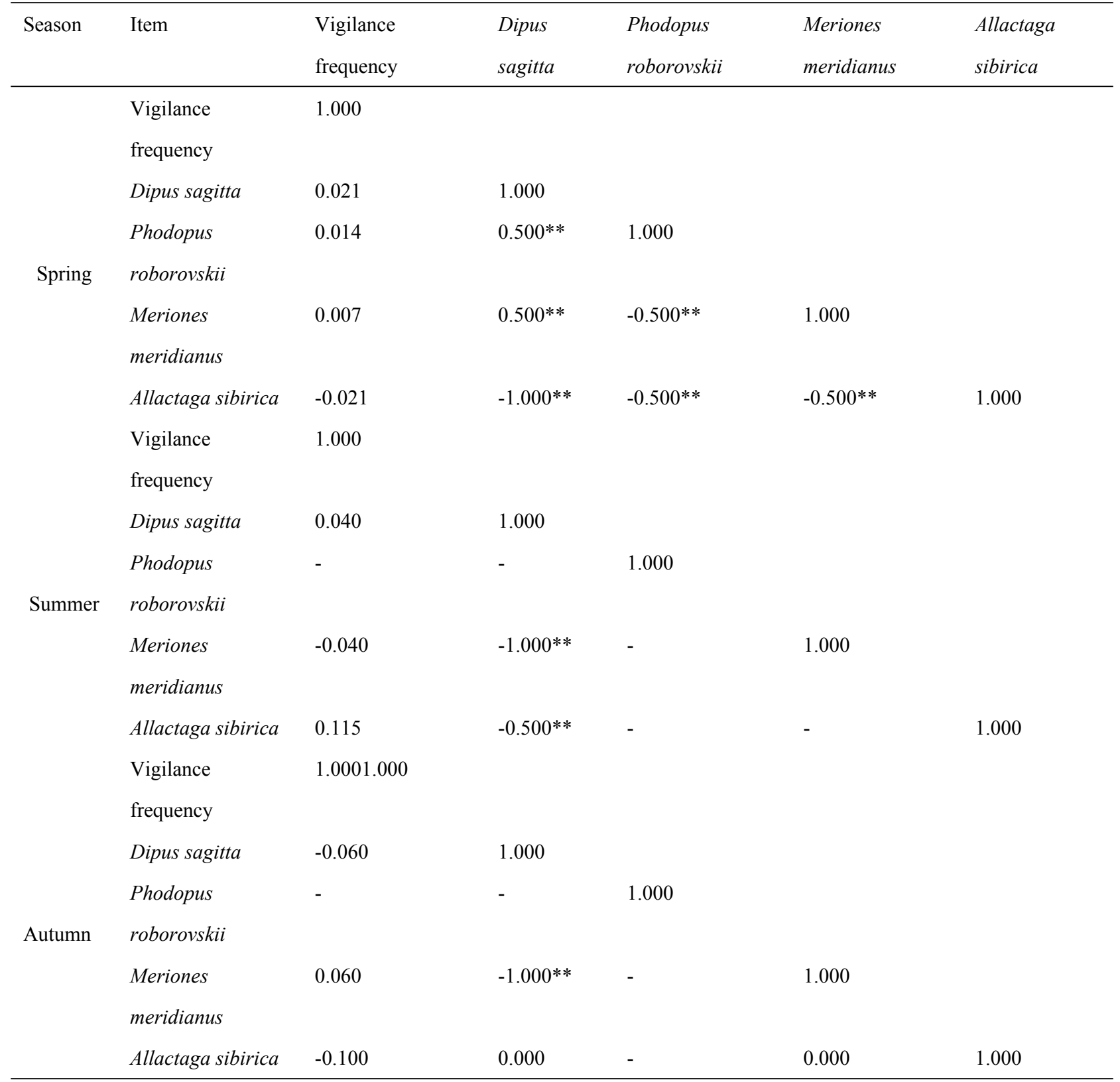

2 
Table 3 (on next page)

Normalization test results 
1

\begin{tabular}{lllc}
\hline Season & Item & Sig. & Normalization or not \\
\hline Spring & Preference food biomass & 0.408 & Yes \\
& Total food biomass & 0.142 & Yes \\
& Activity time & 0.058 & Yes \\
& Activity frequency & 0.072 & Yes \\
Summer & Perceived predation risk & 0.063 & Yes \\
& Preference food biomass & 0.674 & Yes \\
& Total food biomass & 0.434 & Yes \\
& Activity time & 0.158 & Yes \\
& Activity frequency & 0.991 & Yes \\
Autumn & Perceived predation risk & 0.390 & Yes \\
& Preference food biomass & 0.342 & Yes \\
& Total food biomass & 0.161 & Yes \\
& Activity time & 0.270 & Yes \\
& Activity frequency & 0.200 & Yes \\
& Perceived predation risk & 0.056 & Yes \\
\hline
\end{tabular}

2 


\section{Table 4 (on next page)}

Preference index of Allactaga sibirica diet in spring, summer and autumn of 2017 at Alxa Zuo Qi, Inner Mongolia, China.

Bold represents preferred food (index $>1$ ) 


\begin{tabular}{|c|c|c|c|}
\hline Plant species & Spring & Summer & Autumn \\
\hline Achnatherum splendens & 3.433 & 0.830 & 0.342 \\
\hline Agriophyllum pungens & - & 0.556 & 1.656 \\
\hline Agropyron mongolicum & 0.596 & - & - \\
\hline Allium mongolicum & 0.975 & 0.283 & 0.168 \\
\hline Ammopiptanthus mongolicus & - & 0.118 & 0.608 \\
\hline Artemisia ordosica & 0.401 & 0.047 & 0.086 \\
\hline Artemisia sphaerocephala & - & 0.050 & 0.237 \\
\hline Artemisia xerophytica & 0.134 & 0.147 & 0.035 \\
\hline Asparagus cochinchinensis & - & 0.179 & 1.065 \\
\hline Astragalus galactites & 1.275 & 3.403 & 1.306 \\
\hline Atraphaxis frutescens & - & 1.019 & 0.197 \\
\hline Bassia dasyphylla & 1.004 & 0.769 & 0.837 \\
\hline Caragana brachypoda & 2.995 & 1.864 & 0.396 \\
\hline Caragana korshinskii & 0.790 & 0.882 & 0.912 \\
\hline Carex Stenophylloides & - & 1.079 & 0.786 \\
\hline Caryopteris mongholica & - & - & 1.247 \\
\hline Ceratoides intramongolica & 0.140 & 0.242 & 0.276 \\
\hline Cleistogenes songorica & - & 1.488 & 3.695 \\
\hline Convolvulus ammannii & 5.172 & 1.338 & 1.775 \\
\hline Corispermum mongolicum & - & - & 0.248 \\
\hline Cynanchum chinense & - & 0.785 & 0.733 \\
\hline Cynanchum hancockianum & 0.326 & 0.001 & 0.232 \\
\hline Cynanchum thesioides & - & 1.062 & 1.481 \\
\hline Echinops gmelini & - & 1.873 & 2.032 \\
\hline Eragrostis pilosa & - & 3.827 & - \\
\hline Euphorbia humifusa & - & 0.911 & 1.953 \\
\hline Halogeton arachnoideus & - & 0.383 & - \\
\hline Haloxylon ammodendron & 0.199 & 0.058 & 0.660 \\
\hline Hedysarum scoparium & 2.060 & 0.473 & 0.231 \\
\hline Ixeris denticulata & - & 3.120 & - \\
\hline Lepidium apetalum & 0.694 & - & - \\
\hline Lycium ruthenicum & 0.395 & - & - \\
\hline Micropeplis arachnoidea & - & 1.561 & 1.772 \\
\hline Nitraria tangutorum & 0.014 & 0.000 & 1.259 \\
\hline Oxytropis aciphylla & 3.018 & 0.943 & 0.942 \\
\hline Panzeria lanata var. alaschanica & 1.142 & 0.463 & 0.000 \\
\hline Peganum harmala & 0.000 & 0.617 & 1.485 \\
\hline Pennisetum centrasiaticum & 3.854 & 2.280 & 1.914 \\
\hline Phragmites australis & 2.661 & 1.662 & 0.940 \\
\hline
\end{tabular}


Plantago lessingii

Psammochloa villosa

Reaumuria songarica

Salsola collina

Salsola collina

Sarcozygium xanthoxylon

Scorzonera divaricata

Setaria viridis

Sonchus arvensis

Stipa glareosa

Tribulus terrester

\begin{tabular}{lcc}
- & - & $\mathbf{3 . 3 0 5}$ \\
- & 0.292 & 0.674 \\
$\mathbf{1 . 4 4 8}$ & $\mathbf{1 . 0 7 8}$ & 0.245 \\
$\mathbf{6 . 6 6 1}$ & - & $\mathbf{2 . 4 2 9}$ \\
- & $\mathbf{2 . 1 3 0}$ & - \\
0.757 & 0.147 & $\mathbf{1 . 4 1 4}$ \\
- & - & $\mathbf{1 . 1 7 2}$ \\
- & $\mathbf{2 . 9 4 1}$ & $\mathbf{1 . 5 8 2}$ \\
- & 0.924 & $\mathbf{1 . 5 2 8}$ \\
- & $\mathbf{2 . 0 1 2}$ & $\mathbf{1 . 5 4 4}$ \\
- & $\mathbf{4 . 1 0 3}$ & - \\
\hline
\end{tabular}

2 


\section{Table 5 (on next page)}

The catch proportion of rodent in 2017, at Alxa Zuo Qi, Inner Mongolia, China.

The catch proportion of rodent ( \pm se). Different lower-case letters indicate significant difference among seasons at 0.05 level. 
1

\begin{tabular}{lccc} 
Rodent species & \multicolumn{3}{c}{ Catch rate $/ \%$} \\
\cline { 2 - 4 } & Spring & Summer & Autumn \\
\hline Dipus sagitta & $1.523 \pm 0.553 \mathrm{~A}$ & $1.860 \pm 0.877 \mathrm{~A}$ & $0.595 \pm 0.298 \mathrm{~A}$ \\
Phodopus roborovskii & $1.652 \pm 0.869$ & - & - \\
Meriones meridianus & $3.194 \pm 1.576 \mathrm{~A}$ & $2.009 \pm 0.902 \mathrm{~A}$ & $1.936 \pm 0.597 \mathrm{~A}$ \\
$\Sigma$ & $4.846 \pm 0.583 \mathrm{~A}$ & $2.679 \pm 0.515 \mathrm{~B}$ & $2.531 \pm 0.299 \mathrm{~B}$ \\
Allactaga sibirica & $5.234 \pm 0.5773 \mathrm{~A}$ & $3.646 \pm 1.225 \mathrm{AB}$ & $1.486 \pm 0.298 \mathrm{~B}$ \\
\hline
\end{tabular}

2

3 


\section{Figure 1}

Preference food biomass ( \pm se) and total food biomass ( \pm se) in different seasons.

Different lower-case letters indicate significant difference among seasons at 0.05 level.

Different capital-case letters indicate significant difference among preference food biomass and total food biomass at 0.05 level. 


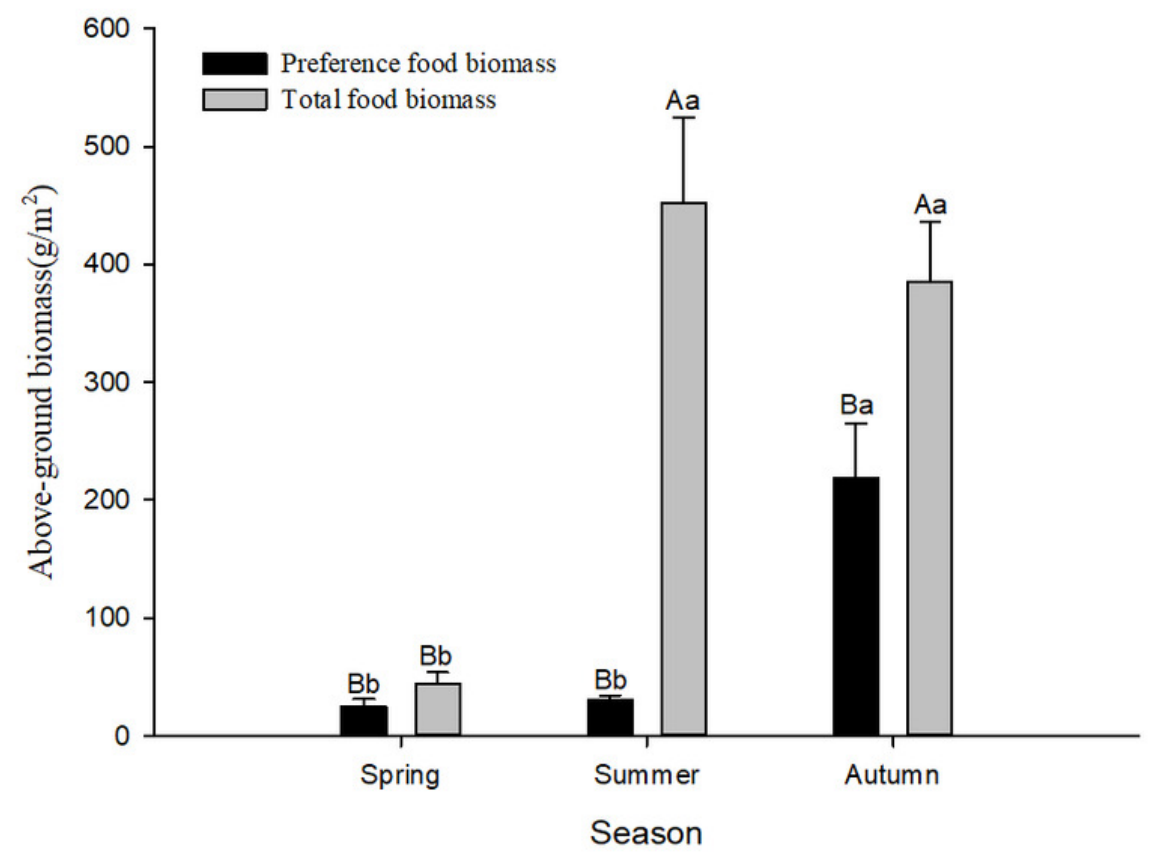


Figure 2

Activity time ( \pm se) and activity frequency ( \pm se) of Siberian jerboa in different seasons.

Different lower-case letters indicate significant difference among seasons at 0.05 level. 

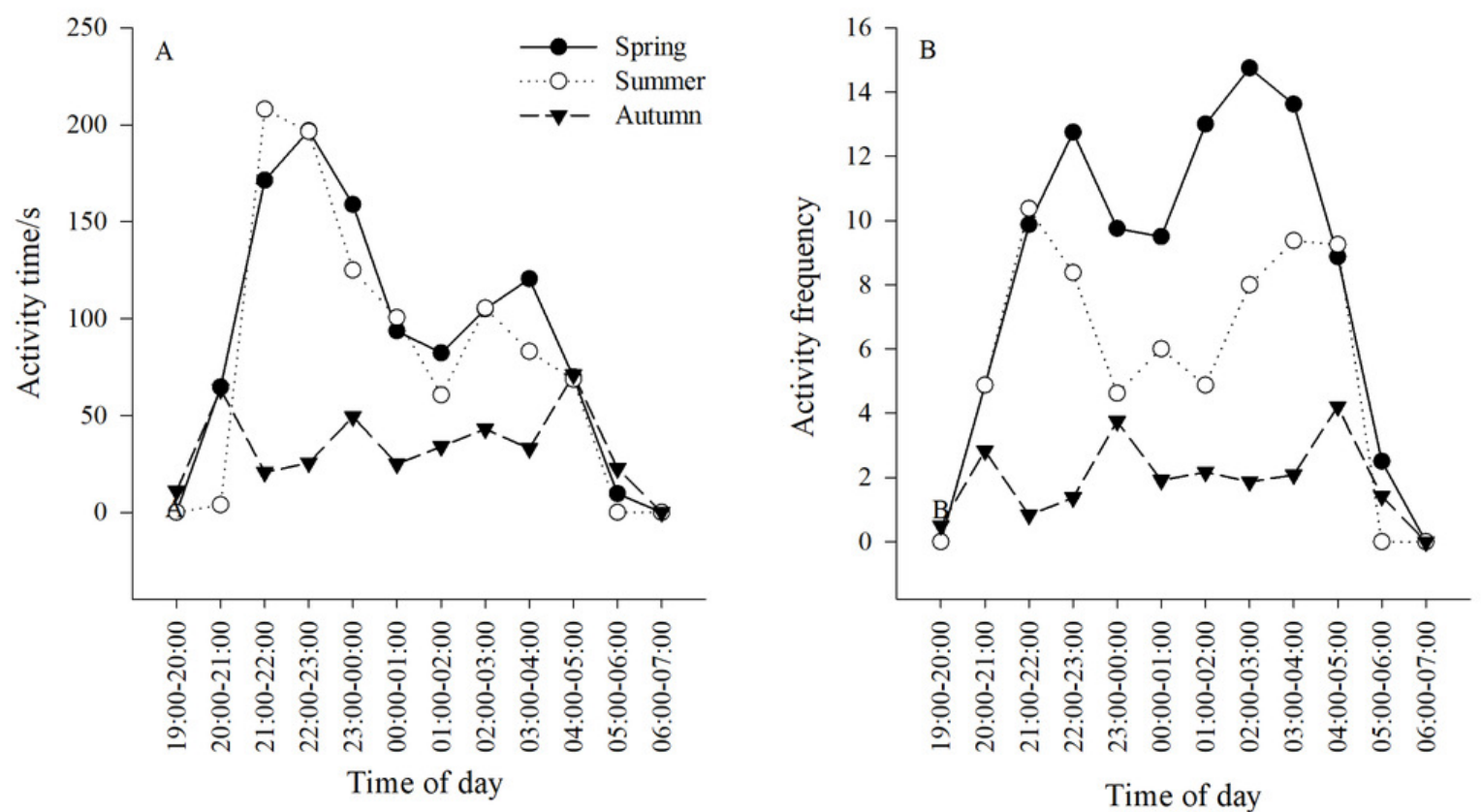

Time of day
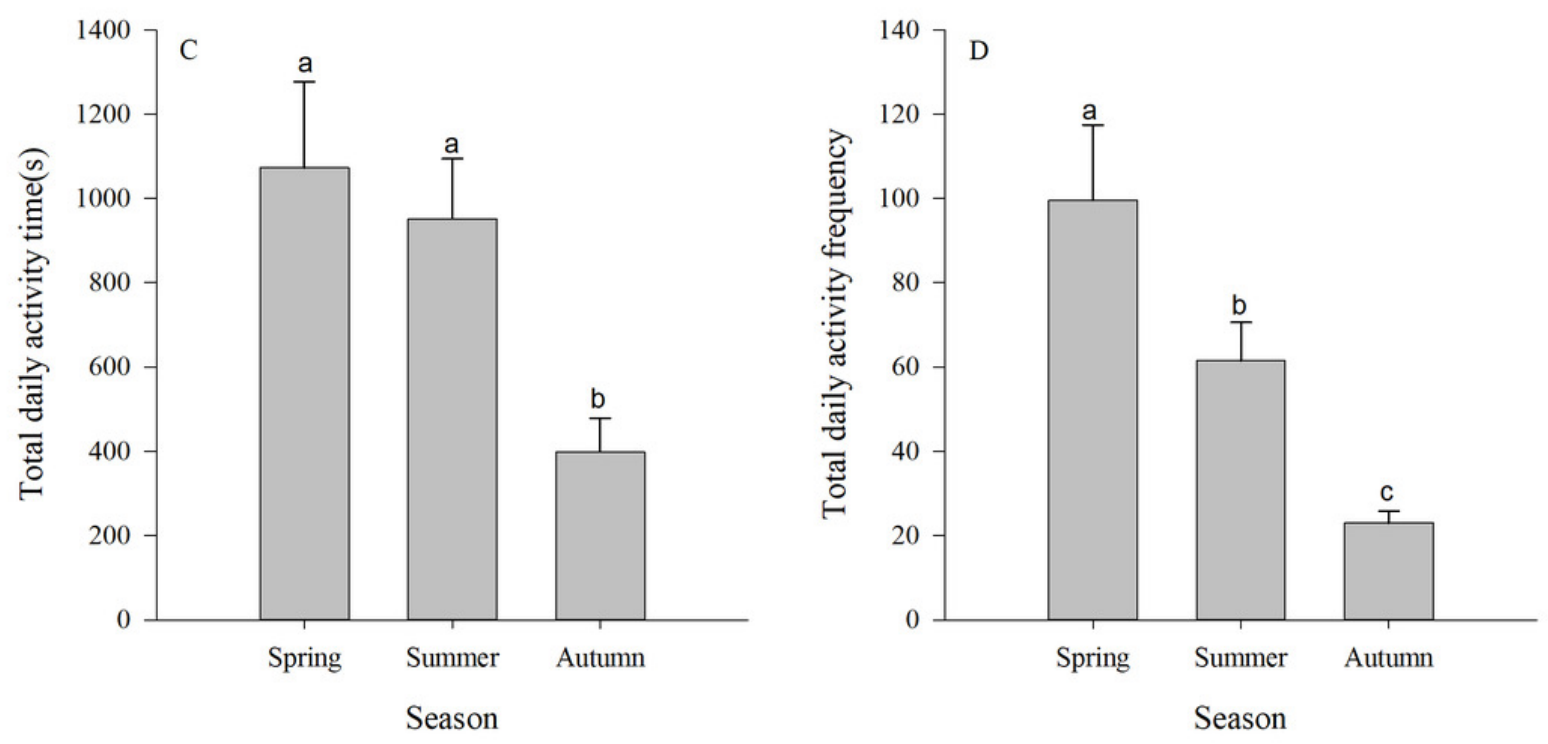
Figure 3

Perceived Predation risk ( \pm se) at different periods of night in different seasons.

Different lower-case letters indicate significant difference at 0.05 level. 

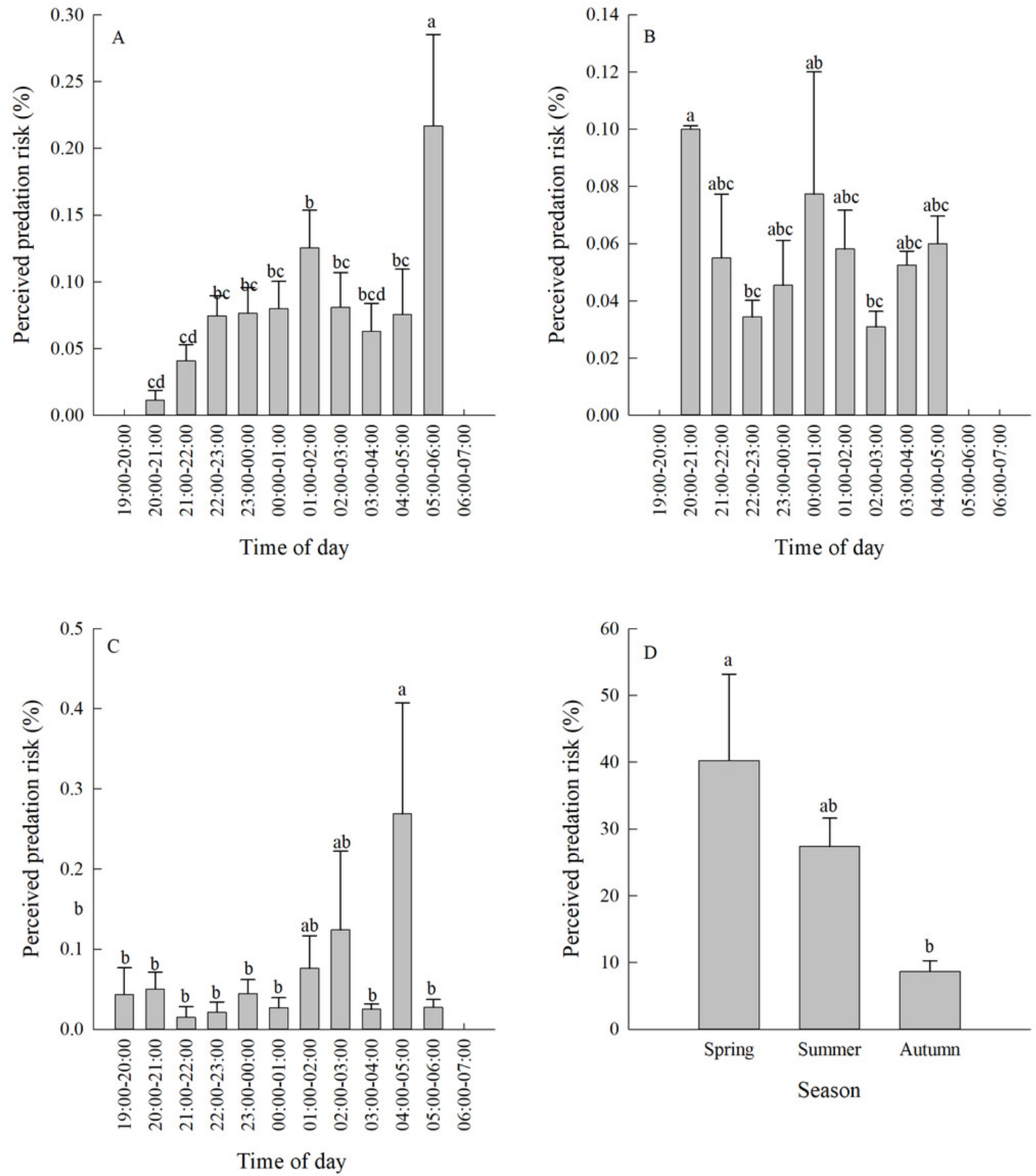


\section{Figure 4}

Ordination diagram showing the results of RDA analysis of different factors and activity time and frequency in spring.

The cosine value between activity time, activity freq uency and different variables represents the correlation between them. A positive cosine value indicates a positive correlation, and a negative value represents a negative correlation. The length of the line segment represents the magnitude of the factor's explanation of activity time and activity frequency. AT: activity time; AF: activity frequency; T: temperature; WS: wind speed ; RH: Air relative humidity; PR: Perceived predation risk; FR: Food resource; InterC: The relative population number of coexisting species; IntraC: The relative population number of Siberian jerboa. 


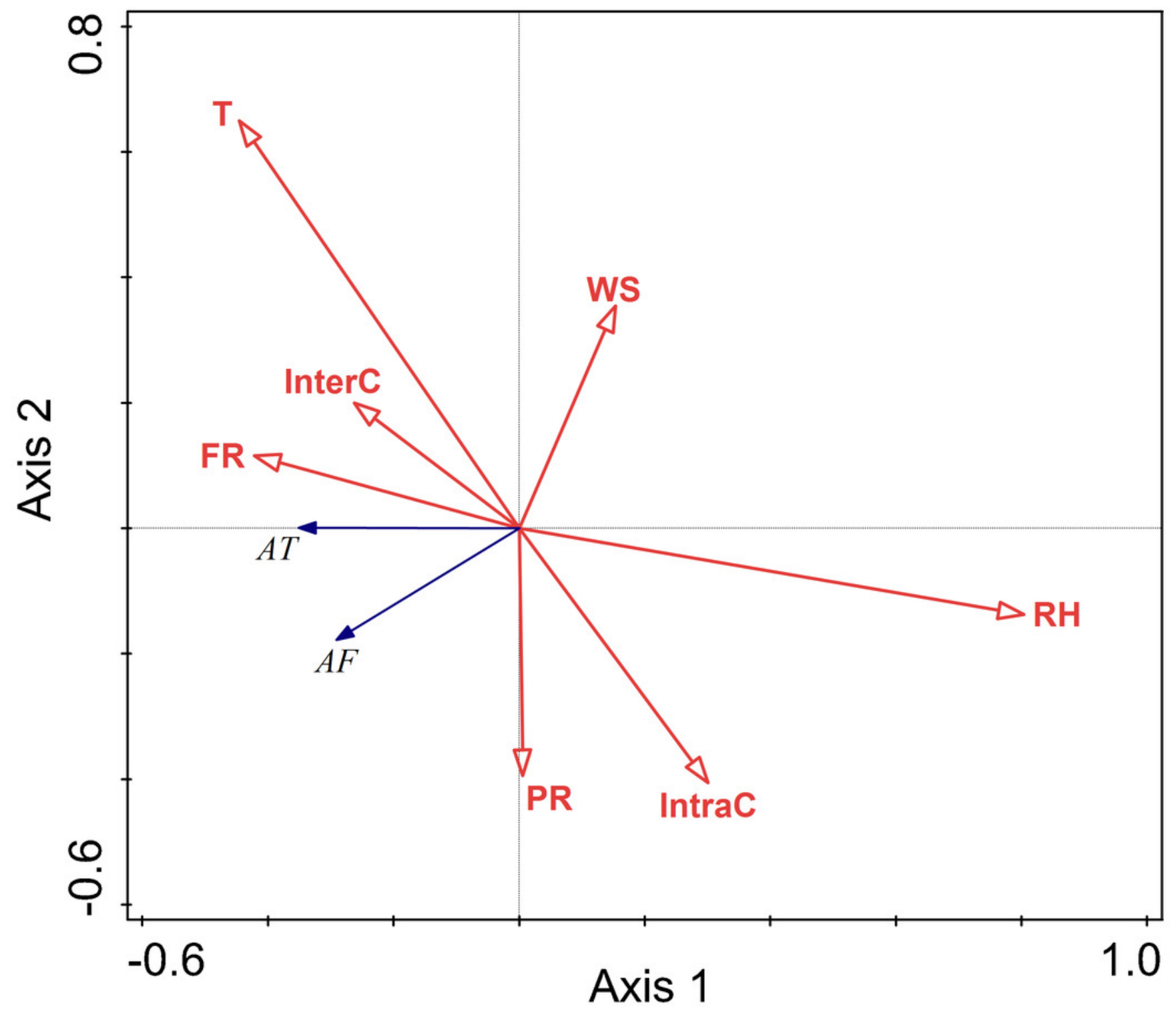




\section{Figure 5}

Ordination diagram showing the results of RDA analysis of different factors and activity time and frequency in summer.

The cosine value between activity time, activity frequency and different variables represents the correlation between them. A positive cosine value indicates a positive correlation, and a negative value represents a negative correlation. The length of the line segment represents the magnitude of the factor's explanation of activity time and activity frequency. AT: activity time; AF: activity frequency; T: temperature; WS: wind speed; RH: Air relative humidity; PR: Perceived predation risk; FR: Food resource; Note: AT: activity time; AF: activity frequency; T: temperature; WS: wind speed; RH: Air relative humidity; PR: Perceived predation risk; FR: Food resource; InterC: The relative population number of coexisting species; IntraC: The relative population number of Siberian jerboa. 


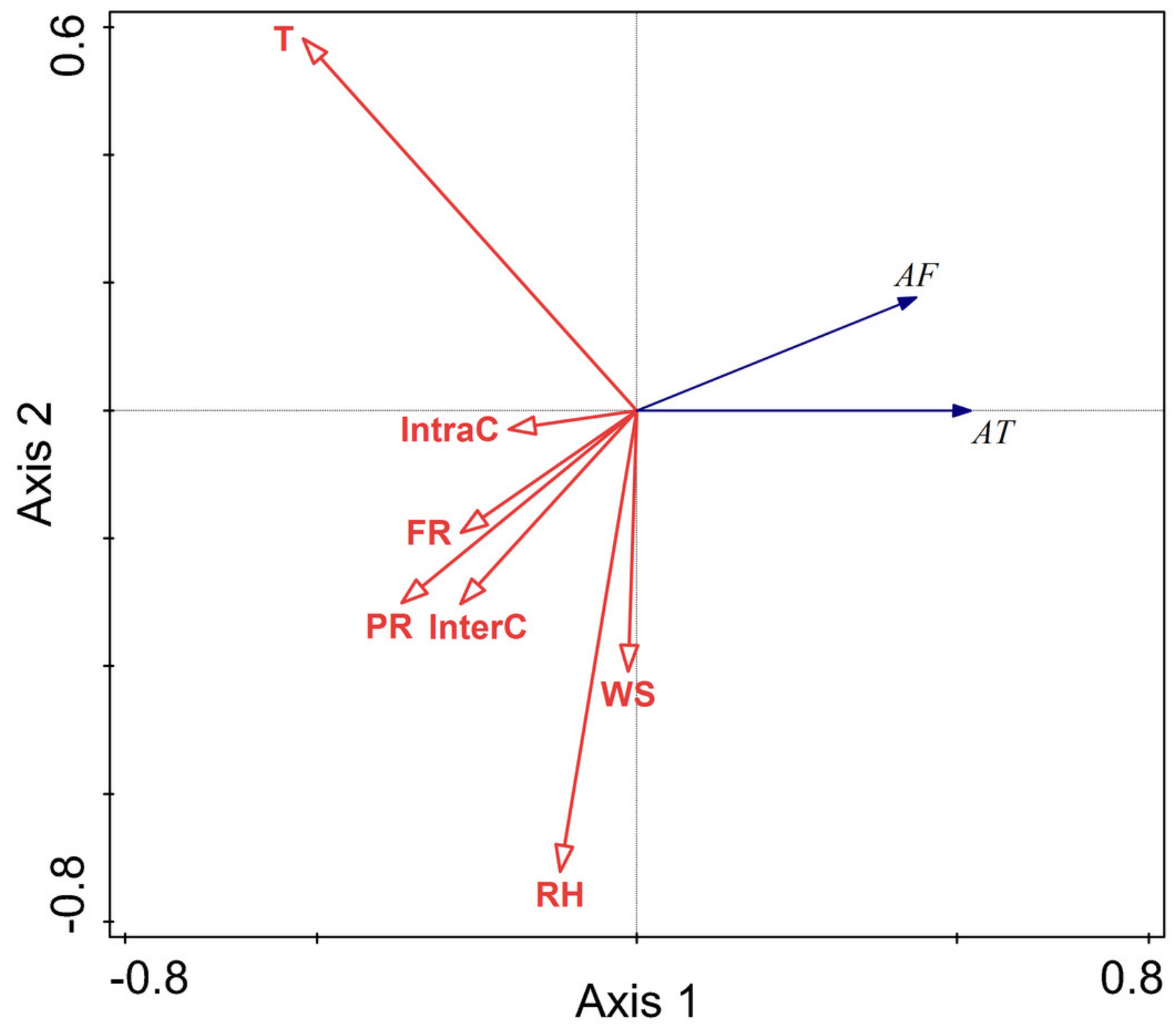




\section{Figure 6}

Ordination diagram showing the results of RDA analysis of different factors and activity time and frequency in autumn.

The cosine value between activity time, activity frequency and different variables represents the correlation between them. A positive cosine value indicates a positive correlation, and a negative value represents a negative correlation. The length of the line segment represents the magnitude of the factor's explanation of activity time and activity frequency. AT: activity time; AF: activity frequency; T: temperature; WS: wind speed; RH: Air relative humidity; PR: Perceived predation risk; FR: Food resource; Note: AT: activity time; AF: activity frequency; T: temperature; WS: wind speed; RH: Air relative humidity; PR: Perceived predation risk; FR: Food resource; InterC: The relative population number of coexisting species; IntraC: The relative population number of Siberian jerboa. 


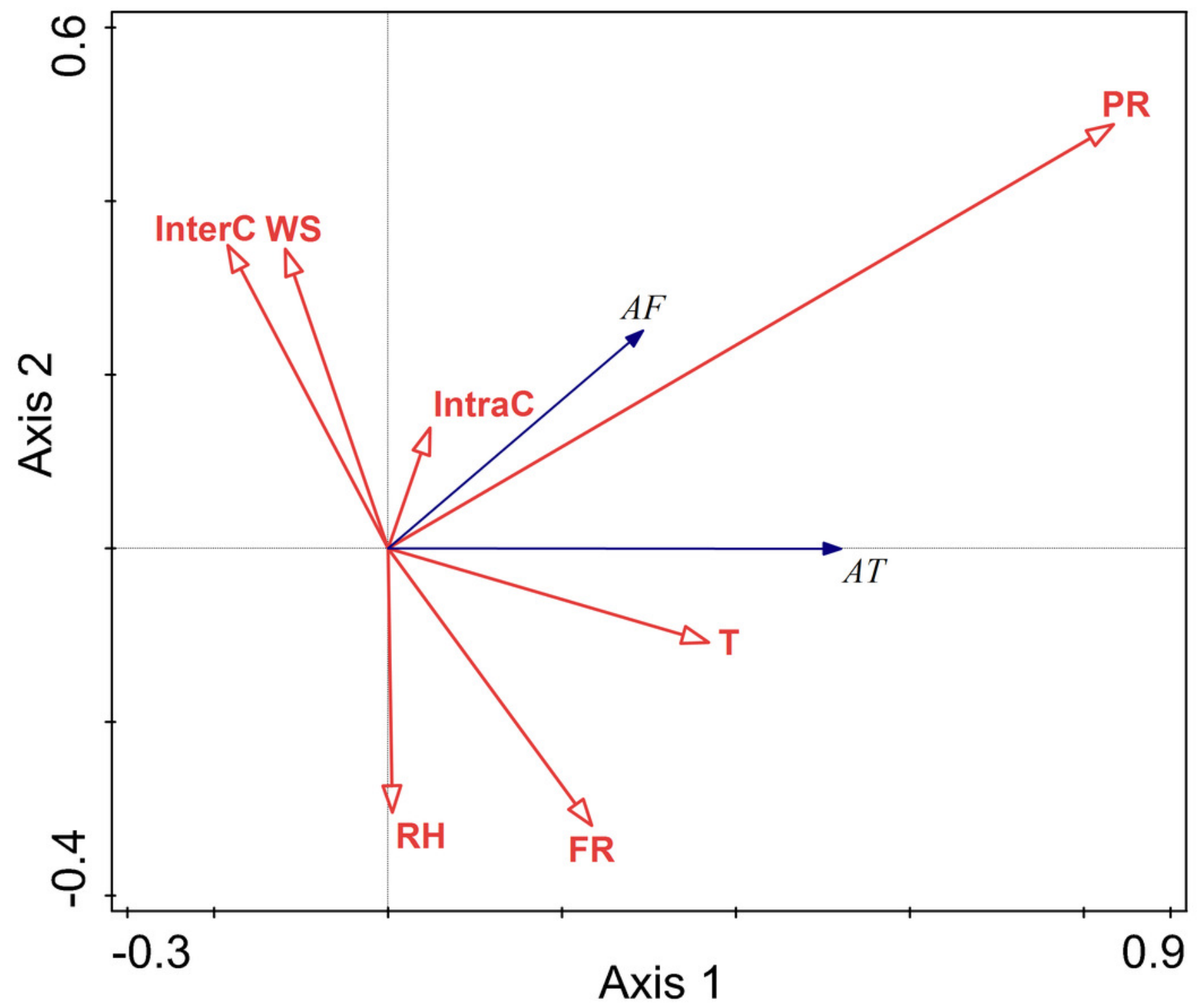

